\title{
Educação musical e novas tecnologias digitais: recursos e estratégias no contexto do canto e da flauta doce
}

Luciane da Costa Cuervo'

Universidade Federal do Rio Grande do Sul (UFRGS) luciane.cuervo@gmail.com 


\section{Resumo}

Este trabalho discute o fazer musical contemporâneo permeado pela cultura digital, em especial no âmbito da utilização de aplicativos na educação musical. Em sua fundamentação, propõe o delineamento de algumas das principais transformações promovidas por recursos associados às novas tecnologias digitais $e$ problematiza possíveis novas habilidades e subsídios necessários aos educadores e músicos hoje. llustram a discussão investigações e práticas pedagógicas da autora na utilização de diferentes recursos empregados em seus projetos de ensino, pesquisa e extensão no fomento de práticas musicais a partir do canto coletivo e da flauta doce. Conclui entendendo que a cultura digital abarca uma grande variedade de recursos, que podem promover e qualificar a performance musical, exigindo para isso novas capacidades do educador musical, bem como de estudantes e profissionais da música. Nesse sentido, também se ampliam as concepções do fazer musical e do próprio conceito de musicalidade.

Palavras-chave: musicalidade; flauta; culture.
This paper discusses contemporary music making permeated by digital culture, especially in the context of the use of apps in Music Education. At its basis, it proposes to outline some of the main transformations brought about by tools associated with new digital technologies, problematising the possible new abilities and inputs necessary for educators and musicians today. The discussion is illustrated by the author's pedagogical research and practices in her use of different tools employed in her projects as a teacher, researcher and in university extension projects in the promotion of musical practices based on group singing and recorder flute. In its conclusion, the paper understands that digital culture encompasses a wide variety of tools that can promote and qualify musical performance, requiring new skills from the music educator, as well as from music students and professionals. In this sense, the conceptions of music making and of the very concept of musicality are also expanded.

Keywords: musicality; flute; digital cultura digital.

\footnotetext{
1 Professora no Departamento de Música do Instituto de Artes da Universidade Federal do Rio Grande do Sul. Graduada em Música/ UFRGS, com ênfase em flauta doce, Mestre em Educação pelo Programa de Pós-Graduação da Faculdade de Educação da UFRGS e Doutora em Informática na Educação/PGIE-UFRGS. Atuou como pesquisadora honorária visitante no Institute of Education of University College London sob orientação do prof ${ }^{\circ}$ Graham Welch (2015-2016). Como intérprete, dedica-se à interpretação de música antiga e contemporânea, havendo estreado inúmeras composições de autores brasileiros. Vem atuando principalmente nos seguintes temas: formação de professores - práticas musicais (voz e flauta doce), musicalidade e cognição musical, performance no contexto da cultura digital.
} 


\section{Educação musical e cultura digital}

Este trabalho se propõe a discutir novas perspectivas do fazer musical sob a ótica do processo de ensino e aprendizagem no contexto da cultura digital. Parte da fundamentação sobre possíveis impactos das Novas Tecnologias Digitais (NTD) nas práticas musicais, apresentando alguns dos principais conceitos que pautam a discussão. Busca problematizar as habilidades e competências que esse cenário demanda no campo da educação musical, tendo em vista a postura aberta e receptiva "ao novo" que o tema exige.

A discussão será delineada a partir de ações da autora que concatenam, se fundamentam e se retroalimentam nas esferas de ensino, pesquisa e extensão, nas quais são utilizados diferentes recursos tecnológicos no fomento às práticas vocais e de flauta doce em projetos de educação musical. No que diz respeito ao conteúdo, será dada ênfase no emprego de aplicativos (apps) envolvendo as práticas musicais, mas também serão contemplados o ambiente virtual de aprendizagem e os diálogos e partilhas inerentes à comunicação contemporânea via aplicativos de mensagens instantâneas como componentes que caracterizam a linguagem na cultura digital.

O cenário atual, vasto e complexo, repercute em novos arranjos que demandam estratégias criativas, logísticas e estéticas próprias, questionando até mesmo o conceito de direito autoral e práticas de difusão, de manipulação e recriação de materiais. Webster (2002) explica que o processo de ensino e aprendizagem também assiste a mudanças, embora por vezes lentas, na incorporação de recursos tecnológicos que visam à qualificação da abordagem e estratégias. Considerando músicos de gerações anteriores e dedicados a gêneros musicais distintos como Glenn Gould ${ }^{2}$ e suas emblemáticas gravações de Bach, João Gilberto 3 e sua exigente acuidade técnica da sonoridade amplificada nas apresentações e Naná Vasconcelos ${ }^{4}$, exímio improvisador com manipulação eletrônica ao vivo, é possível perceber que a incorporação de tecnologias modernas à interpretação musical vem ocorrendo de maneira intensa ao longo dos séculos 20 e 21. E, graças ao fenômeno da internet, hoje é possível acessar, analisar e discutir todas essas performances, nos mais distintos ângulos e interfaces, com acesso gratuito a boa parte dessas obras. Um questionamento que surge diante de produções como essas é o motivo pelo qual essas tecnologias, largamente utilizadas há mais de 50 anos, tardam a ser incorporadas na área da educação musical.

O recente relatório da The Music Commission Panel (2019), intitulado "Reafinando" nossas ambições acerca da aprendizagem musical" (tradução livre da autora), grupo cuja composição congrega profissionais das áreas de performance musical, educação, política cultural e mídia, argumenta que a música é elemento central na vida social e

\footnotetext{
$2 \quad$ Pianista canadense que viveu entre 1932 e 1984.

3 Compositor, cantor e violonista nascido em Juazeiro em 1931 e falecido em 2019.

$4 \quad$ Percussionista, compositor e improvisador nascido em Recife em 1944 e falecido em 2016.

$5 \quad$ Outros significados possíveis para a palavra original em inglês retuning neste contexto seriam "reajustando" ou "sintonizando". Título original: Retuning our ambition for music learning.
} 
econômica moderna e defende que a partir dela há melhora na autoconfiança, nas realizações acadêmicas e nas habilidades sociais, aspectos cruciais na vida dos jovens. Nesse documento são apontados práticas e resultados excepcionais de experiências na área, contudo é feito o alerta de que ainda prevalece a disparidade na provisão material das escolas e um descompasso perturbador na compreensão sobre como os jovens se envolvem com a música hoje. Embora realizado no Reino Unido, essa mobilização possui significado global e pode subsidiar discussões também no Brasil.

Nessa linha de pensamento, é relevante alertar que o contexto social e político brasileiro caracterizado a partir dos conflitos de 2016 vem dissipando as conquistas almejadas nos anos anteriores no País, em especial acerca de programas de educação, cultura e ciência. Os cortes dramáticos de recursos para projetos de ensino e pesquisa, a depreciação da educação pública intimidada por pressupostos impostos pelo mercado financeiro e a interrupção de programas de investimentos em democratização do acesso a recursos, como a banda larga no Brasil, vão de encontro às demandas da temática abordada nesse trabalho no que diz respeito às NTD e à música. Exemplos disso podem ser citados, como o fato de o Ministério da Ciência, Tecnologia e Inovação (MCTI) ter sido fundido com o de Comunicação, embora tenham em essência objetivos e ações dessemelhantes ${ }^{6}$ (DINIZ, 2018); a extinção do Ministério da Cultura, contrariando manifestações de universidades, instituições e profissionais do meio cultural de todo o país; e a nova postura do Ministério da Educação, o qual assistiu a uma perturbada troca de ministros nos últimos anos e tem feito reiterada defesa da privatização da educação, em detrimento de políticas públicas de assistência e democratização de acesso a populações economicamente carentes (ANDES, 2019). Esse conjunto de ações pode significar um prejuízo nos âmbitos social, cultural e econômico da sociedade, mas, em relação ao foco deste trabalho, pode significar a dificuldade e até a exclusão do acesso da população aos recursos comuns das NTD.

O acesso à educação musical no Brasil historicamente se depara com percalços. A pesquisa em andamento com 66 jovens e adultos (maiores de idade) realizada sob coordenação da autora ${ }^{7}$ mostrou que $68 \%$ dos participantes residentes na cidade de Porto Alegre e região metropolitana não tiveram acesso à educação musical na escola, e somente uma pequena parte do grupo teve educação musical por alguns (poucos) anos seguidos, em geral em atividades extracurriculares, como mostra o Gráfico 1, que visa organizar as respostas à pergunta: "Você teve acesso à educação musical na escola (educação básica)?".

\footnotetext{
6 Conforme matéria da Plataforma Política Social e Le Monde Diplomatique Brasil(2018) sobre manifestos de entidades científicas representativas brasileiras, a pauta do MCTI "é baseada em critérios de mérito científico e tecnológico, com programas desenvolvidos e avaliados por comissões técnicas", enquanto ao Ministério das Comunicações caberiam "relações políticas e práticas de gestão distantes da vida cotidiana do MCTI".

$7 \quad$ Projeto de Pesquisa "Práticas Musicais de Pessoas com Amusia: um estudo sobre usos e funções das tecnologias", realizado na Universidade Federal do Rio Grande do Sul (UFRGS) em parceria com a Universidade Federal de Ciências da Saúde de Porto Alegre (UFCSPA) e University College London (UCL -Inglaterra). Financiamento da Fundação de Amparo à Pesquisa do Rio Grande do Sul (FAPERGS) e fomento da Pró-Reitoria de Graduação em Pesquisa e de Extensão (PROPESQ e PROREXT/UFRGS), com previsão de ocorrência 2016-2021.
} 


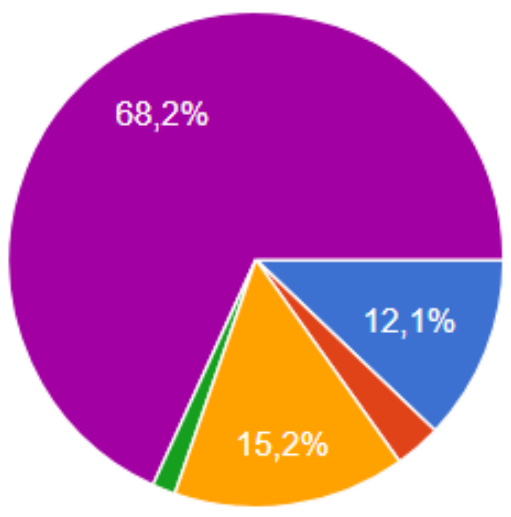

Sim, durante um a três anos no currículo há mais de 4 anos

Sim, por vários anos no currículo há mais de 4 anos

Sim, em atividades extraclasse há mais de 4 anos

Sim, há menos de 4 anos

Não tive educação musical na escola

Gráfico 1: Índice de acesso à educação musical dos participantes.

Recorte da pesquisa da autora, coleta via questionário on-line Google Forms.

Esses dados, de certa forma, corroboram os achados da investigação de Wolffenbbüttel (2017) sobre a presença (ou falta) da educação musical nas escolas públicas municipais do Rio Grande do Sul. Após um amplo levantamento naquele estado, a pesquisadora concluiu que, embora se façam presentes algumas atividades no campo da educação musical nas escolas públicas municipais sul-rio-grandenses, ainda predomina a carência do acesso à área como componente curricular. Dos 497 questionários enviados (para cada município gaúcho), 44,04\% retornaram com alguma resposta positiva em relação à educação musical na escola. Desse percentual, constatou-se uma atividade musical diversificada, em muitos casos não sistematizada e, em geral, realizada fora do currículo, com oferecimento esporádico e pouco abrangente na comunidade escolar.

Cruzando ambas as pesquisas mencionadas, é possível elucubrar um cenário de perpetuação da falta de acesso à educação musical na escola, visto que um trabalho trata de jovens e adultos acima de 18 anos e outro da educação escolar de crianças e jovens.

Esses achados fortalecem o que também apregoa a Music Commission (2019) acerca da necessidade de promover a educação musical na condição de área de formação integral do ser humano. Enquanto no Brasil ainda se discute a importância da presença da linguagem musical no currículo escolar, sob constante ameaça de exclusão por parte de políticas públicas que desvalorizam a área (CUERVO et al., 2019), o referido relatório internacional centraliza sua preocupação na promoção do progresso de jovens em seus conhecimentos musicais, compreensão e habilidades no campo. As conclusões da $\mathrm{Mu}-$ sic Commission (2019, p.20), alertam de modo pertinente que ${ }^{8}$ :

- Existe uma grande inconsistência na oferta de música em escolas;

- As barreiras de custo para as famílias representam uma desigualdade de acesso à educação musical;

- Houve uma resposta inadequada ou ineficiente sobre como os jovens usam a tecnologia em sua experiência de música;

8 Tradução da autora. 
- Há suporte insuficiente além do primeiro acesso a programas para alunos que desejam progredir na educação musical;

- As escolas precisam de maior apoio na prestação de um rico currículo de música que se concentra nas principais habilidades musicais;

- Recursos e organizações não estão funcionando juntos efetiva e suficientemente para apoiar todos os aprendizes em seu desenvolvimento.

Esse relatório também defende que a musicalidade é algo próprio do ser humano e reforça a ideia da educação musical como uma linguagem cujo acesso deveria ser universal, dada a sua importância. O documento menciona que modos diversos de fazer música, especialmente a apreciação, fazem parte do cotidiano da sociedade (THE MUSIC COMMISSION, 2019). Essa afirmação segue em consonância com os dados coletados pela autora, os quais mostraram que mais de $90 \%$ do público participante possui o hábito de ouvir música com frequência diária, de acordo com o Gráfico 2.

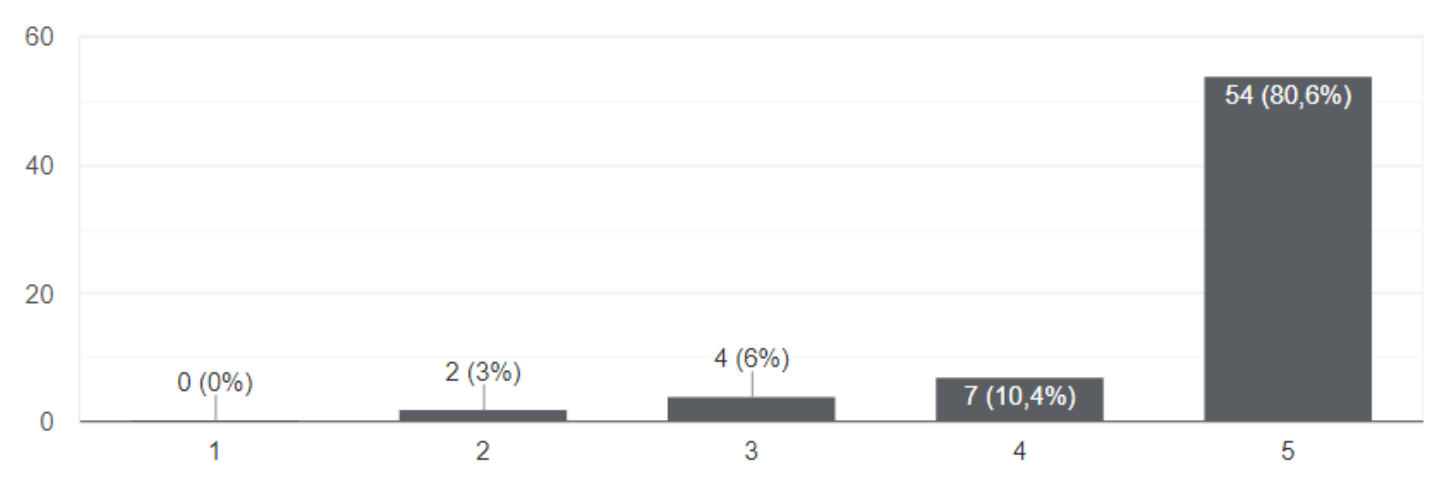

Gráfico 2: Participantes que escutam música (escala de 0 a 5, para nunca a diariamente). Recorte da pesquisa da autora, coleta via questionário on-line Google Forms.

Assim, denota-se um alto valor atribuído à apreciação, com frequência de escuta de diversas horas por dia, no mesmo público que, em sua maioria, não teve acesso à educação musical como área curricular na formação escolar. Pelo menos no que diz respeito à apreciação, as tecnologias parecem preencher uma lacuna entre jovens e adultos, antes perpetrada na formação escolar.

Para Silva (s/d), o professor precisa se dar conta de quatro principais aspectos no que diz respeito à implementação da cibercultura ${ }^{9}$ nos processos educativos: a atual transição da mídia clássica para a mídia on-line; a tecnologia digital demanda um hipertexto próprio para este contexto; a interatividade é a modalidade comunicacional primordial neste novo cenário, em oposição ao modelo tradicional de comunicação; é necessária uma tomada de consciência por parte do educador no sentido de potencializar a comunicação e a aprendizagem através de mecanismos comuns da internet. 
No campo da música, Bauer (2014) prediz que o uso das NTD não corresponde ao descarte das abordagens tradicionais, mas ao seu enriquecimento. Ele alerta para a necessidade de que os professores de música se mantenham receptivos e ativos, promovendo a interação entre estudantes de todas as idades e dos saberes e práticas oriundos externamente à escola.

A rede global da internet condensa variadas edições da mesma obra musical, de suas partituras e de vídeos de interpretação, gravações realizadas por diferentes músicos, em repertórios dos mais variados períodos da história da música. Seja na realização de performance historicamente orientada, seja em música experimental improvisatória, a cultura digital fornece meios de estudo, ensaio, registro, performance e difusão inéditos até duas décadas atrás e como nunca se observou antes na história da música. $O$ acesso a essas produções mudou radicalmente, tornando-se mais democrático e amplo.

Formas inovadoras de interpretação musical mediadas pelas NTD geram novas concepções de expressividade musical, nas quais o músico amplia o conceito de instrumentista e a relação com seu instrumento (incluindo a voz), transmutando a forma de comunicação com o público e sua interação com os espaços físicos e acústicas correspondentes. Cabe aos educadores e professores de música em geral pensarem modos de incorporar essas reflexões ao planejamento pedagógico na área de educação musical.

\section{Performance musical e ubiquidade}

A configuração da performance musical é impactada de maneira significativa pelas NTD no que concerne à expansão de subsídios materiais, cognitivos e físicos do indivíduo. Essa performance deve ser pensada devidamente contextualizada ao tempo e vivência sociocultural de seus sujeitos. Estéticas, estratégias e abordagens influenciadas vêm transformando as relações entre compositores, intérpretes e o público apreciador, e também se manifestam nos processos de concepção, produção, performance e consumo de música, conforme discutiu CUERVO (2016) em sua pesquisa.

As variadas formas de interação com a música abarcam processos de apreciação e análise de performances por meio de gravações e produções audiovisuais publicadas em sites como o YouTube, procedimentos envolvendo a linguagem digital, recursos de apoio à performance ou instrucional que fazem uso de dispositivos móveis, softwares e aplicativos. O que parece acontecer, em alguns casos, é que a naturalização do uso desses recursos provoca a sua invisibilidade, ou seja, o seu emprego torna-se tão corriqueiro que acaba por ser ignorado nos levantamentos da área em relatos de músicos, uma das constatações da investigação realizada pela autora (CUERVO, 2016).

Nessa perspectiva, o contexto se coloca como agente desafiador ao delinear dois principais cenários possíveis. Se, por um lado, o acesso às NTD promove a democratização de manipulação e implementação de recursos diversos, do nível mais elementar ao mais avançado, essa nova configuração da performance musical também pode exigir uma ressignificação de habilidades técnicas, criativas e expressivas de todos os sujeitos do processo, incluindo então os professores de música, os estudantes, os músicos amadores e profissionais, entre outros. 
Interessante observar que a suposição de forte presença das NTD na construção da performance musical contemporânea é discutida de modo tímido também na produção científica da área de música, um tanto aquém da relevância da temática. O levantamento abrangente realizado por Gabrielsson (2003) ilustra essa afirmação, cuja detalhada análise de mais de 200 trabalhos publicados entre os anos de 1995 e 2002 encontrou um aumento do número de investigações empíricas sobre a performance musical. Nessa investigação, o pesquisador constatou predominância em discussões de medição de desempenho e modelos de performance e prática interpretativa, com destaque para pesquisas que contemplam o planejamento em performance, ligado ao campo de pedagogia da performance. Embora se proponha a discutir a performance musical dos séculos 20 e 21, sua discussão não analisa em profundidade papéis e funções das NTD, abordando esse aspecto de modo superficial no exame de algumas categorias elencadas, mesmo constatando forte presença de recursos tecnológicos eletrônicos e digitais nos contextos investigados. Gabrielsson (2003) aborda pesquisas de mensuração da performance, feedback e modelos interpretativos, cuja formatação envolve diferentes técnicas com recursos de informática, instrumentos musicais acústicos e elétricos, incluindo análises de gravações de ensaios e de performances ao vivo, mas tangencia a discussão da temática. Embora ciente da importância de trabalhos como este, pode ser motivo de crítica que, num levantamento sobre a performance musical o qual se propõe a ser abrangente, a relevância das NTD tenha sido aparentemente ignorada ao não consistir num parâmetro analisado de forma específica junto aos demais.

O panorama traçado exige uma abertura "ao novo" e reflexão sobre a prática, permeadas por uma permanente curiosidade investigativa. Há um certo desencontro entre as práticas consolidadas e os novos recursos, cujas constantes atualizações tecnológicas e epistemológicas se fazem presentes. Como metaforicamente explana Gohn (2013), "é como perseguir a própria sombra: quando se chega ao ponto intencionado, o objeto de interesse já está um pouco mais a frente" (GOHN, 2013, p.14). Esse delay pode vir a desmotivar mentalidades mais conservadoras e resistentes a mudanças, mesmo que gradativas.

Outra linha de argumentos que pode elucidar esse cenário baseia-se no conceito de "tecnofobia", relativo ao medo que as pessoas podem ter das tecnologias (digitais) e da mediação das máquinas de modo geral. Numa pesquisa de caráter inovador e exploratório, Oh e colaboradores (2017) procuraram conhecer impactos dos recentes progressos em jogos de inteligência artificial (IA) na concepção dos usuários. Entre complexos dados coletados, que também atestam a necessidade de maiores discussões na área, a investigação mostrou o temor que as pessoas podem vir a desenvolver quando pensam que um nível avançado de IA possa superar e até mesmo dominar capacidades humanas. Do mesmo modo, foi identificada uma postura de confronto e hostilidade entre humanos e a IA, corroborada por referências de ameaça e descarte de habilidades humanas em produções audiovisuais, como games e filmes de ficção científica. Os participantes da pesquisa mencionam que, se antes as máquinas se limitavam a realizar tarefas mecânicas e repetitivas, agora conseguem alcançar altos níveis de complexidade, o que pode se refletir inclusive na diminuição de empregos e na substituição de habilidades criativas, como nas artes, incluindo a música (OH et al., 2017). 
Ainda que a implementação e a democratização de técnicas, difusão e informações sobre música tenham sido disseminadas amplamente pelo uso de apps e da internet de modo geral, em alguns aspectos podem provocar uma homogeneização e até mesmo a banalização de uma produção musical.

A ideia do "novo substituir o antigo" não confere com a verdade e não abrange a complexidade do tema no campo da música, principalmente quando levado em consideração o complexo e dinâmico processo educativo. A permanente postura de abertura ao novo não significa, de forma alguma, o rejeite do que veio antes, inclusive em termos de tecnologias. Promover o descarte de ideias e produções anteriores sem problematização frente ao novo é uma espécie de fortalecimento do conceito de obsolescência programada também no campo epistemológico. Trata-se de uma analogia cruel.

Se, ao invés de investir em estratégias de capacitação e democratização do acesso às NTD aos músicos profissionais e amadores, aos estudantes e seus professores, a atitude for a de repelir indivíduos que não dominem recursos comuns à cultura digital, imperará, então, uma atitude de desvalorização aos saberes e práticas acumulados, às trajetórias de vida e de experiências dos sujeitos. Explicando o conceito de obsolescência programada em termos materiais, Padilha e Bonifácio (2013, s/p) afirmam que:

\begin{abstract}
Na sociedade da obsolescência induzida, tudo acaba em lixo. Quanto mais rápida e passageira for a vida dos produtos, maior será o descarte. A publicidade é o motor que faz toda essa dinâmica funcionar. Esse modelo de sociedade baseada na estratégia da obsolescência planejada está sendo determinante no esgotamento dos recursos naturais (que ocorre na etapa da produção) e no excesso de resíduos (que ocorre na etapa do consumo e do descarte).
\end{abstract}

Talvez o cerne deste debate sobre NTD e performance musical seja compreender o que é insubstituível na linguagem musical humana e o que a caracteriza enquanto discurso expressivo e único. Também é relevante refletir sobre a experiência humana - e humanizada - e como as NTD podem qualificar as relações construídas, e não ameaçá-las.

As especificidades humanas nos processos criativos envolvendo a música tornam os músicos agentes insubstituíveis no fazer musical, segundo Kramer (1997). Ainda que identifique habilidades humanas que possam ser exitosamente supridas por recursos tecnológicos, o pesquisador defende que as NTD, em sua essência, possuem potencial de interferência e colaboração na qualificação de estudos individuais e coletivos, nas estratégias técnicas e procedimentais da construção da performance e de sua execução para um público. Ele acredita, também, que o domínio sobre conhecimentos elementares de mixagem, equalização e registros, é, enfim, um quesito obrigatório para o músico que não quer ser considerado não alfabetizado no campo da música (KRAMER, 1997). Suas afirmações, propostas há mais de duas décadas, seguem plenas de sentido no momento atual.

Até um século atrás, a música resultante de estudos, ensaios e performances era limitada ao seu tempo e espaço. Tinha por característica a efemeridade. Mesmo com o advento das gravações, esse recurso ainda ficou restrito a determinados públicos du- 
rante boa parte do século 20 devido à inacessibilidade material dessa tecnologia. Cuervo e colaboradores (2017) discutiram as mudanças pelas quais a musicalidade humana vem passando, especialmente em relação ao impacto da Cultura Digital. Segundo os autores, os processos de criação, grafia, performance ao vivo e gravada, assim como a sua difusão, apreciação e consumam modificaram radicalmente a relação do sujeito com a música, assim como o próprio conceito de musicalidade (CUERVO et al., 2017).

Hoje, qualquer produção pode circular facilmente em termos globais e até mesmo instantaneamente por meio de lives (transmissões ao vivo) e transmissões publicadas imediatamente após o seu registro. A internet congrega redes sociais, sites de compartilhamento, como o YouTube, assim como aplicativos de mensagens instantâneas como o WhatsApp, blogs, sites, vlogs, cuja audiência pode rapidamente tornar um conteúdo "viral", propagando-se de forma intensa e de alcance incalculável através da rede.

Flores (2014) entende que a utilização de dispositivos móveis com função voltada às práticas musicais engloba capacidades de portabilidade, mobilidade e conectividade, que promovem acesso a pessoas que antes não tinham como estudar música formalmente.

O fazer musical através da internet, assim, ganha contornos de ubiquidade nunca antes imaginados. As atividades do compositor e regente Whitacre podem dar uma ideia sobre essa afirmação, ilustrando o potencial congregador que a performance musical mediada pela internet pode apresentar, ao propiciar a conexão de pessoas de diferentes culturas e locais muito remotos. Em 2009, Whitacre teve acesso a um vídeo de uma admiradora de seu trabalho, a qual gravou a parte de soprano de uma música de sua autoria (WHITACRE, 2011). Esse material suscitou a ideia de disponibilizar gratuitamente na internet a sua obra Lux Aurumque, propondo que pessoas de qualquer região do mundo exercitassem as partes correspondentes à sua voz, guiados também pelo vídeo com sua regência da obra. Desse modo, embora separados geograficamente, os integrantes de seu coro virtual poderiam construir uma performance individual em harmonia com a interpretação coletiva, enviando seus vídeos caseiros, cuja edição ficou por conta de membros de sua reduzida equipe de trabalho. Assim, o vídeo pioneiro deste projeto conectou 50 coralistas e logo se tornou um viral no YouTube, superando um milhão de acessos em apenas um mês. Considerando exitosa a experiência, o compositor montou posteriormente um coro com mais de 20 mil vídeos de 2 mil cantores residentes em 58 países diferentes, de todos os continentes.

A performance da música "Sleep"10, cuja estética visual virtual resultante pode ser conferida na Fig. 1, foi criada considerando cada esfera um grupo de cantores de determinado país, ao mesmo tempo em que sua regência figurativa gravada em vídeo conduz ao centro. A iniciativa do compositor Whitacre mostrou ser possível unir os mais variados músicos, cantores amadores e profissionais, engajados em solfejo e execução de obra erudita vocal, numa performance estruturada com base em estudo autônomo, ubíquo e fundamentalmente mediada pelas novas tecnologias.

10 Performance disponível no YouTube e na página pessoal do compositor pelo link:

http://ericwhitacre.com/the-virtual-choir/history/vc2-sleep. 


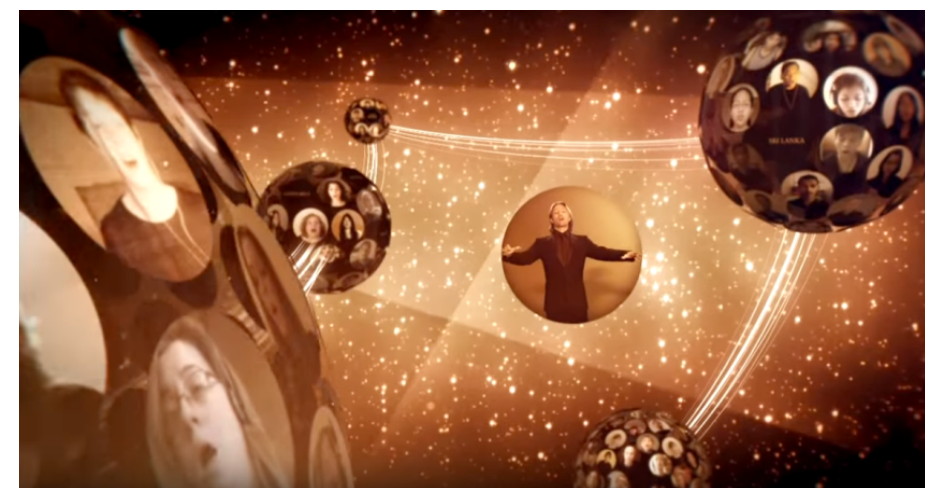

Fig. 1: Coro virtual, performance de Sleep, de Whitacre (2011). Fonte: Página pessoal de Whitacre ${ }^{11}$.

A partir de coleta de dados entre relatos dos participantes, Whitacre (2011) expõe experiências que denotam um sentimento de pertencimento e de conexão do grupo, embora seus membros estivessem distantes fisicamente, delineando uma profunda aproximação promovida pela música e mediada pela internet. Em suas palavras:

Duas coisas me impressionaram profundamente nisso. A primeira é que os seres humanos vão confrontar a distância que for necessária para encontrar e se conectar uns aos outros. Não importa a tecnologia. E o segundo é que as pessoas parecem estar passando por uma conexão real. Não foi um coro virtual. (WHITACRE, 2011) ${ }^{12}$.

Considerando as dificuldades de dedicação de carga horária presencial atualmente, configurando-se como obstáculo à reunião de pessoas em horário e local comum, iniciativas como esta apresentada podem consistir numa opção de complemento de ensaios presenciais tradicionais ou até mesmo de substituição de procedimentos na modalidade presencial. Baseadas no conceito de ubiquidade, vê-se que experiências como a de Withacre (2011) podem nortear práticas coletivas e estratégias pedagógicas de cursos de música na modalidade a distância, semipresencial, pedagogia da alternância ou enriquecer as atividades presenciais.

De acordo com Teixeira (2010), a articulação de culturas e contextos variados ultrapassa a ligação material de equipamentos, num novo contexto que expande as redes de trocas e de crescimento possibilitado pela partilha de vivências socioculturais. Como resultado desse cenário, há a criação de um "novo território", segundo o autor, como um novo local de limites desconhecidos, que está também sujeito à manipulação de dados, a processos de aculturação e promoção desmedida de controles externos. Entretanto, esses novos territórios podem servir de base para a construção de conhecimento, quando contemplados em planejamentos pedagógicos que o visem como aliados do processo de ensino e aprendizagem.

\footnotetext{
11 Disponivel em: http://ericwhitacre.com/the-virtual-choir/history/vc2-sleep.

12 Tradução da autora, a partir da transcrição do vídeo da conferência.
} 
Cabe mencionar, contudo, que, embora haja equipamentos eletrônicos disponíveis em uma variada gama de modelos e valores, quando se fala em música, a qualidade sonora produzida é requisito crucial no processo. Este, contudo, é um elemento excludente em termos materiais, ainda mais em países em desenvolvimento, com acentuadas disparidades econômicas.

Considera-se que o acesso à internet e a velocidade de conexão são aspectos relevantes, e por isso também se deve defender políticas públicas de democratização sobre esses recursos e de inclusão digital em seus usos e funções. Embora relativamente disponíveis em termos de acesso, uso e expansão pelo mundo, como aponta relatório da ONU (2015), recursos que exigem internet e boas conexões nem sempre são alcançados com facilidade em países como o Brasil, o qual possuía programa de expansão da internet chamado Banda Larga para Todos $^{13}$, cuja implementação sofreu interrupções de toda a ordem de investimentos desde os conflitos políticos de 2016.

A capacidade ubíqua promovida tanto pelas redes quanto pelo caráter de portabilidade de aparelhos cada vez menores e mais potentes indubitavelmente impacta de forma positiva a popularização de aplicativos de toda ordem. $O$ acesso a dispositivos móveis, como o celular, e à internet é relativamente amplo em públicos de perfis socioeconômicos diversos, e metade da população brasileira acessa a internet somente via celular (IBGE, 2018) ${ }^{14}$. Em pesquisa anterior realizada com 50 músicos profissionais e amadores da cidade de Porto Alegre e região metropolitana, Cuervo (2016) encontrou que $86 \%$ das pessoas possuíam celulares do tipo smartphones na época de ocorrência do levantamento. Em investigação recente da autora junto a 66 pessoas (não músicos), apenas duas possuem celulares simples, sem recursos de internet móvel, e $100 \%$ possuem celular.

Dentre os dispositivos utilizados para ouvir música, o celular lidera a preferência (85\%), somado a outras opções, conforme expõe o gráfico a seguir, concebido em recente levantamento da autora:

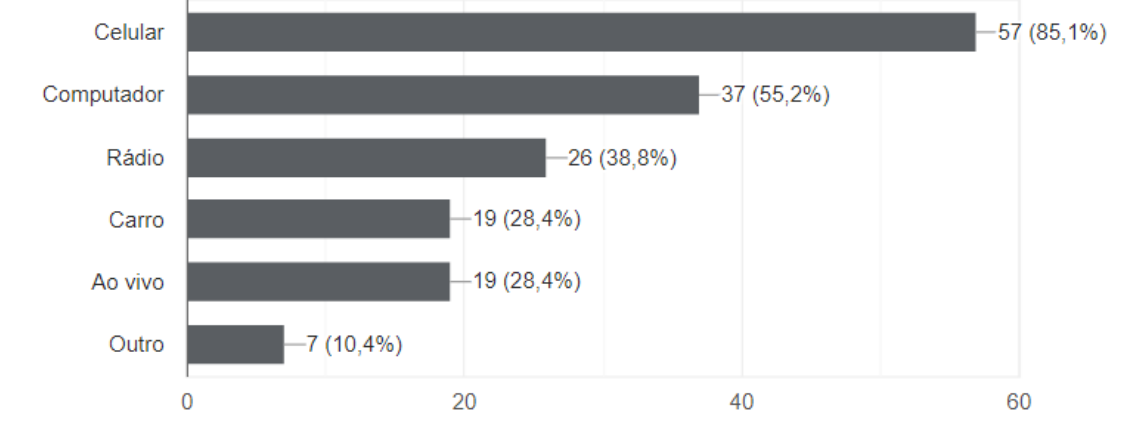

Gráfico 3: Participantes que escutam música (escala de 0 a 5, para nunca a diariamente)

Fonte: Recorte da pesquisa da autora, coleta via questionário on-line Google Forms.

13 Este programa foi sumariamente modificado a partir de 2016, sofrendo drástico corte de verbas, e atualmente não há divulgação oficial sobre qualquer ação da área junto à sociedade brasileira.

14 Síntese de Indicadores Sociais (SIS) divulgada pelo Instituto Brasileiro de Geografia e Estatística (IBGE, 2018). 
No âmbito do ensino e aprendizagem de música, mesmo estando professor e aluno em ambientes geograficamente distantes, entram alguns recursos muito utilizados: ambientes virtuais de aprendizagem (AVA) ou uso pedagógico de redes sociais e aplicativos de trocas de mensagens. Quanto ao primeiro tipo, a experiência da autora versa na esfera do Moodle Institucional UFRGS, plataforma de aprendizagem que permite uma série de intervenções, interações e produções individuais ou colaborativas, além de arquivamento de materiais e processo avaliativo. Um AVA como este promove uma grande autonomia para o docente configurar o template e aplicar a sua metodologia através dos recursos disponibilizados pela plataforma, como questionários com diferentes tipos de perguntas e respostas, fóruns de discussão e postagem de materiais, incluindo vídeos e links interativos, chats, enquetes, provas e atividades síncronas ou assíncronas. Também fomenta a autonomia discente, na medida em que oferece um espaço de interação assíncrona, no qual o estudante poderá escolher quando e como deseja navegar e quais materiais e atividades deseja fazer no momento da sua entrada.

Por outro lado, se o docente não se preocupa em aprender e se atualizar no uso dos recursos que se transformam constantemente, ou em estimular os estudantes a interagirem no ambiente, o espaço virtual e as suas propostas podem ser tão improdutivos e desprovidos de sentido quanto uma sala de aula presencial apática - com o agravante de ser mediado por uma máquina.

\section{Softwares e aplicativos para o canto e a flauta doce}

Tanto o material didático e técnico/instrucional produzido para o ensino da música e de instrumentos musicais (incluindo a voz) quanto as estratégias pedagógico-musicais concebidas podem ser qualificados ao contemplarem aspectos da tecnologia digital e linguagem virtual, potencializadas em seu alcance e difusão pela internet. Nesse sentido, pode-se afirmar que essas transformações em curso, que se refletem em novas exigências e capacidades do músico contemporâneo e na sua práxis, precisam ser contextualizadas também no processo educativo-musical, como defendem diversos autores (WEBSTER, 2002; HARGREAVES, 2005; GOHN, 2013).

Primeiramente, é pertinente elucidar os conceitos de software e aplicativo. Geralmente os aplicativos móveis são abreviados por "app", cuja definição é de softwares com funções específicas para uso em dispositivos móveis, especialmente do tipo smartphones. Por haver uma mescla de termos e significados entre software, programa e aplicativo, o presente trabalho adota a abreviação apps para aplicativos de celular, enquanto software fica relacionado a programas de computador.

Orientações e práticas musicais através de apps vêm tomando forma na conduta musical de aprendizagem e autoaprendizagem de músicos amadores e profissionais, em estudos autodidatas, colaborativos ou conduzidos por um professor, em todos os níveis de desenvolvimento. Em consonância com esse ponto de vista, Xydas (2014) afirma que a utilização de aplicativos na aula de música beneficia o aprendizado do instrumento, especialmente no que concerne à autonomia e à criatividade do estudante. $O$ pesqui- 
sador aponta que o ato de intercalar seus conhecimentos e habilidades adquiridos com o uso de instrumentos virtuais para os reais promove a criatividade na prática musical. Para ele, o uso de softwares livres e dispositivos digitais é uma forma de democratizar o acesso aos estudos e práticas musicais (XYDAS, 2014).

Como defendem Webster (2002) e Hargreaves (2005), o emprego de softwares na prática musical é um domínio que faz parte das exigências da formação do músico hoje, e essas demandas se espraiam no escopo de competência do educador musical.

Há recursos gratuitos de caráter colaborativo que promovem e qualificam a produção, o exercício, o registro e a difusão da performance musical. De acordo com Gohn (2015), um aporte tecnológico de qualidade para a implementação de contextos musicais demanda pelo menos três elementos: 1) um software de áudio que possua qualidade, devido à exigência de eliminação de compressão de dados; 2) internet de rápida conexão e capacidade, de modo a permitir o correto funcionamento do software; 3 ) recursos devidamente adaptados aos instrumentos musicais e suas especificidades, especialmente no que concerne à captação e à reprodução de áudio.

Uma ferramenta acessível e pertinente para o estudo de música consiste no metrônomo virtual Metronome Beats, proposto por Stonekick ${ }^{15}$, que tem disponibilidade gratuita na Google Store ${ }^{16}$ e possui compatibilidade com o sistema Android. Ele apresenta de 1 a 300 batimentos por minuto, contempla padrões de andamentos historicamente convencionados, permite elencar a acentuação da batida e consequente métrica, em diversos timbres e tons (frequências), e ainda oferece a possibilidade de salvar as configurações de preferência do usuário, entre outros recursos. Pode-se afirmar, portanto, que recursos desse tipo superam em larga escala as possibilidades de aparelhos digitais ou mecânicos comuns do mercado e são difundidos de modo gratuito. A viabilidade econômica de produções dessa espécie é originada por anúncios comerciais nos sites ou embutidos na instalação dos aplicativos.

A utilização de tablets e iPads é cada vez mais comum entre os músicos, visto que podem ser transportados e manipulados com facilidade em viagens e no espaço do palco, diminuindo a tensão das viradas de página com procedimento programado, facilitando a leitura de transições e ritornelos da obra musical, registrando digitalmente escolhas interpretativas, entre outros recursos. A virada de página de partitura digital com a própria cabeça do músico é promovida por softwares como o PiaScore ${ }^{17}$, no iPad, ou com o uso de pedais AirTurn ${ }^{18}$ e PageFlip ${ }^{19}$ para iPad ou de forma programada, conforme o tempo regular concebido previamente de modo personalizado no dispositivo móvel. Somado a isso, é possível programar o zoom de foco, formato e tamanho do material, prever a alternância e o retorno das partes da música que poderão ser manipuladas a

15 Fonte: http://www.stonekick.com/.

16 Google Store é uma loja virtual de apps do Android oferecida pelo Google para dispositivos móveis que possuem o sistema Android.

17 Disponível em: https://itunes.apple.com/us/app/piascore-smart-music-score/id406141702?mt=8.

18 Disponivel em: http://www.airturn.com/.

19 Disponível em: http://www.pageflip.com/. 
partir de um toque. A performance ao vivo, nesse sentido, ganha novos contornos, que mudam a relação do músico com as limitações impostas pelo formato tradicional no papel, contribuindo ainda para ampliar o grau de interatividade e autonomia no contato com a partitura, assim como aumenta de forma extraordinária a capacidade de arquivamento de peças em formato digital, em acervos na nuvem ou em dispositivos.

\section{Ideias no campo da voz}

Retomando os dados apresentados no início deste trabalho, é possível afirmar que há uma demanda reprimida em termos de práticas musicais entre adultos que não tiveram acesso à educação musical em sua formação escolar. Nesse sentido, também é primordial valorizar o canto, considerando que a voz é um recurso natural e que a prática de canto promove uma série de benefícios amplamente discutidos (WELCH, 2003; 2005; 2012). Aliar recursos dentre as NTD à prática de canto potencializa a autonomia e a diversidade de estímulos que enriquecem o desenvolvimento do estudante. $A$ análise de alguns recursos que vêm sendo estudados e implementados pela autora pode elucidar essas afirmações.

Os aplicativos de troca de mensagens instantâneas, por exemplo, permitem o envio de áudios e vídeos, bem como diálogos e ligações instantâneas, podendo agregar valiosos recursos para as práticas musicais e processos educativos. Apps como o WhatsApp possibilitam um prolongamento da aula presencial, promovendo o estudo autônomo através da disponibilização de materiais previamente produzidos para a qualificação do estudo do indivíduo.

A intervenção em formato de oficina de música que está sendo realizada nesse momento por equipe interdisciplinar coordenada pela autora em projeto de pesquisa prevê em seu planejamento ampla utilização de recursos dentre as NTD. Foram preparados áudios para a distribuição em grupo de app de mensagens via WhatsApp ${ }^{20}$, a fim de estimular o estudo dos participantes fora do ambiente da aula e em suas vozes e naipes específicos. Dessa maneira, a equipe de educadores musicais prepara um áudio através de recursos como o Audacity, com vozes separadas de cada canção, ou de vozes em uníssono ou cânone, conforme a natureza do repertório, e esse arquivo é compactado em versão leve para ser posteriormente distribuído aos participantes, tornando-se um modelo vocal afinado e qualificado em termos musicais, técnicos e acústicos acessível ao grupo. Através do mesmo app também são repassados links de gravações, artigos e materiais de estudo em formatos diversos, antecipando ou reforçando conteúdos abordados nos encontros presenciais.

Essa estratégia vem sendo utilizada intensamente por regentes do projeto em atuações profissionais em ambientes paralelos muito distintos, obtendo êxito inclusive em coros amadores, embora esta seja a primeira experiência num ambiente controlado e com protocolos da metodologia detalhadamente registrados no projeto de pesquisa. É interessante notar que, para esses regentes, o WhatsApp vem com elemento substituto 
de recursos anteriormente utilizados, em especial as gravações em fita $\mathrm{K} 7$ e CDs, os quais eram registrados individualmente para membros dos coros por eles conduzidos. A velocidade de gravação do áudio, bem como de sua difusão, foi acentuadamente alterada, ao mesmo tempo que o investimento material necessário foi reduzido.

Um dos objetivos do referido projeto de pesquisa é compor um conjunto de estratégias e registros da experiência aplicada junto a não músicos iniciantes, a fim de fornecer também subsídios a educadores musicais que venham a se interessar em implementar recursos semelhantes.

Dentre os recursos na área da voz cantada, Bauer (2014) cita softwares de acompanhamento autorregulado, de gravação de áudio, de instrumentos acústicos, eletrônicos e digitais incluindo os virtuais, dispositivos móveis, para notação musical e leitura de partitura, lousa interativa digital, dentre outras possibilidades que podem apoiar o acompanhamento rítmico/melódico e tutoriais de autoaprendizagem ou estudo autônomo de modo geral. O feedback visual, ou VTF (Visual Feedback Technology), é um dos mecanismos possibilitados por softwares específicos para o canto.

Em termos históricos, o ensino de canto perpetua o modelo mestre-aprendiz, cujo núcleo é a abordagem expositiva do professor, o qual é um modelo que transmite as informações necessárias em busca do progresso do estudante, como explicam Callaghan et al. (2004). Os pesquisadores entendem que essa é uma ferramenta eficaz no ensino do canto, no entanto a comunidade docente ainda é reticente à sua utilização (CALLAGHAN et al., 2004), seja devido aos custos, seja por algumas limitações de pedagogias que ignoram as possibilidades da VFT. Nos estudos realizados por Wilson et al. (2015), foi constatado que a VFT ideal para iniciantes fornece informações mais detalhadas e contextualizadas, enquanto a tecnologia quando direcionada a cantores com informações prévias pode diminuir a quantidade de informações, no sentido de suavizar a carga cognitiva engajada no processo.

Cuervo e Dias (2019) analisaram softwares de feedback visual para a prática de canto, encontrando aspectos positivos no seu emprego. Os pesquisadores constataram, no entanto, que persiste uma lacuna de trabalhos publicados, em especial no Brasil e no idioma português. Em suas práticas de ensino de música enriquecidas pela investigação realizada, os autores entendem que o uso de softwares pode promover uma qualificação do processo educativo-musical, considerando também que a voz é um "instrumento invisível", cujo ensino ainda predomina o emprego de metáforas. Essa abordagem tradicional é predominada por analogias da produção vocal e aparelho vocal no canto, muitas vezes sem base científica, e, quando estruturam de forma basilar a metodologia, sem complemento de outras estratégias, podem apresentar lacunas no que concerne ao conteúdo e à didática do ensino do canto. Esse delineamento subjetivo, que caracteriza o ensino de canto por metáforas, reforça uma metodologia centrada no professor, na qual o estudante precisa lidar com conceitos e informações complexos transmitidos de modo abstrato.

Por outro lado, as VFT promovem um recurso adicional na prática de canto, permitindo que o estudante exercite aspectos técnicos em casa, com um suporte de qualidade e segurança na orientação (CUERVO e DIAS, 2019). Conforme o trecho de uma 
canção de trabalho brasileira apresentado pelos autores em seu trabalho no estudo com o software Sing\&See (Fig. 2), é possível constatar que a cantora (contralto) realiza a linha melódica de modo coerente e afinado ${ }^{21}$.

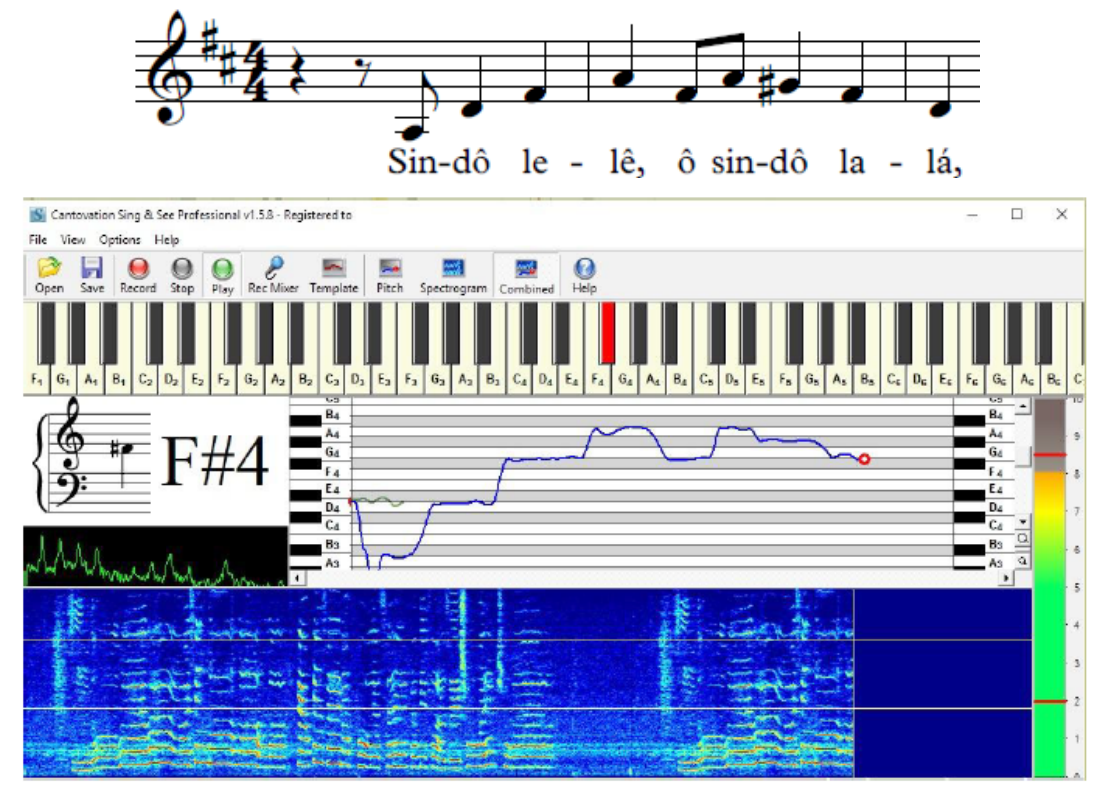

Fig. 2: Produção gerada pelo software Sing\&See, a despeito do trecho melódico ilustrado na partitura.

Segundo Cuervo e Dias (2019) ${ }^{22}$, práticas vocais de canto do estudante ou do profissional se beneficiam pelo acesso a um material gráfico que possibilita visualizar, com precisão e respostas concretas, aspectos da interpretação. No caso deste software, é possível ter acesso a diversos recursos de estudos e práticas na versão gratuita, embora a versão paga (em torno de 100 dólares) tenha recursos bastante apropriados para a prática de canto com auxílio do feedback visual. Dentre os principais recursos oferecidos pela versão gratuita, os autores apontam a visualização das notas em suas alturas, oscilações referentes a vibratos, assim como desvios ou quebras da linha melódica, entre outros aspectos.

A construção da performance por parte do usuário do software adquire mecanismos de tomada de consciência acerca da própria execução. É preciso ressaltar, no entanto, que essa tecnologia pode inibir pessoas com severos problemas de afinação, por exemplo, gerando frustrações pela inabilidade em solucionar os problemas identificados. Ou, como constataram Wilson e pesquisadores (2015), se a pessoa já tem um certo grau de conhecimento na prática do canto, um nível de detalhamento maior pode causar uma sobrecarga cognitiva. Para isso, cabe também ressaltar o papel de um professor capacitado, que saberá conduzir o processo de forma acolhedora, produtiva e prazerosa em busca de progresso na interpretação do estudante.

\footnotetext{
210 exemplo da partitura é em tom distinto do cantado, porém o contorno melódico e as relações intervalares permanecem iguais. 22 Trabalho apresentado pelos autores em congresso recente da ISME, com anais no prelo. Canção de trabalho coletada por Renata Mattar, intitulada "Sindo lelê", das pisadeiras de folhas de cacau de Ilhéus, na Bahia.
} 


\section{Ideias no contexto da prática instrumental}

O conceito de execução instrumental no contexto da cultura digital também sofreu expansões epistemológicas ${ }^{23}$. Os instrumentos musicais virtuais, por exemplo, consistem em performance instrumental. Mulder (1994) propõe uma analogia a um instrumento convencional, considerando o virtual uma interface gestual que permite a síntese de um gesto moldado como som, gerando novas formas de execução a partir das diversas partes do corpo humano. $O$ autor inclusive problematiza o relevante debate da reunião entre música, movimento e dança, apartados nos fins do século 18 na música erudita eurocêntrica (MULDER, 1994).

Scholoss (2002) entende que praticamente qualquer gesto pode ser reconhecido por instrumentos virtuais, assim como o julgamento de qual é importante ou não nas escolhas interpretativas. Ele acredita que, através da experimentação e pesquisa, os gestos dos instrumentos musicais convencionais podem ser expandidos na música eletrônica e eletroacústica, explicando a possibilidade de assumir uma natureza híbrida no que se refere ao timbre. Embora defensor da qualidade que pode ser alcançada pela execução em instrumentos virtuais, Scholoss (2002) alerta para elementos visuais, emocionais e expressivos que precisam ser considerados na performance com instrumentos deste tipo, para que os processos comunicativo e expressivo entre o músico e o público não sejam desprestigiados.

O conceito contemporâneo para instrumento musical virtual pode ser definido como um software ou aplicativo (app) que produza sons com intenção musical. Ele pode ser inserido num instrumento ou equipamento, com ou sem ligação a um dispositivo sequenciador, podendo ser comandado por meio de um controlador (como um teclado, um computador ou outro tipo de ferramenta). Entre seu conjunto de recursos, é relevante citar plugins de instrumentos virtuais de samplers (samples) ${ }^{24}$, como o VSTi (Virtual Studio Technology instrument) ou o Dxi (DirectX instrument) ${ }^{25}$, utilizados através de softwares de edição de áudio e música.

Um vasto campo em potencial consiste dos games. Como trilha sonora, a música possui importância vital na identidade e estética do jogo. Dentre recursos para a prática musical, embora haja menor publicação sobre o tema, denota-se grande oferta e demanda de jogos que ensinam a tocar instrumentos musicais. Uma das produções pioneiras foi o Guitar Hero ${ }^{26}$, no qual o jogador precisa seguir a música dedilhando um

\footnotetext{
23 Embora a voz seja considerada um instrumento musical pelos autores, o foco neste momento será dado a instrumentos de sopro, especialmente a flauta doce.

24 Sampler é um equipamento que permite gerar e executar fragmentos sonoros de instrumentos musicais de acordo com a necessidade (DAVIES, s/d).

25 Plugins DXi - DXi (DirectX) são um recurso que pode ser utilizado em conjunto com qualquer aplicativo host compatível. A grande maioria dos DirectX Instruments são sintetizadores de software, no entanto também há muitos samplers e caixas de ritmos. Fonte: http://www. hitsquad.com/smm/cat/PLUGINS_DXI/.
}

26 Desenvolvido pela Harmonix Music Systems, lançado pela RedOctane para console de videogame Playstation 2 (2005). 
controle do tipo joystick ${ }^{27}$, depois complementado por uma réplica lúdica de um instrumento musical, possuindo os botões (no lugar de cordas) correspondentes às funções solicitadas nas ações de simulação e de execução.

Como discutem Aliel e Gohn (2012), alguns jogos mais modernos podem ser encarados como recurso de autoaprendizagem musical, paralelamente à atividade de lazer. Com jogos como Rock Band 3, de acordo com os autores, a inovação tecnológica amplia o ato de lazer e promove subsídios para a execução musical efetiva por meio de um codificador MIDI que captura as notas musicais emitidas por instrumentos reais, caracterizando potenciais recursos para processos educativo-musicais. Disso decorre uma mudança de paradigma, na qual a simulação por meio de réplicas lúdicas de instrumentos musicais passa a se modificar para a configuração de instrumentos musicais concretos, e não meros acessórios ou brinquedos (ALIEL; GOHN, 2012).

No âmbito dos instrumentos de sopro, as diferentes alterações ou articulações de dispositivos eletrônicos e digitais vêm expandindo o espectro de sonoridades e repertórios possíveis. A ocarina, por exemplo, trata-se de um aerófono em forma oval oriundo de tempos bastante antigos e encontrado em culturas ocidentais e orientais. Wang (2014) dedicou-se à concepção de apps para dispositivos móveis e tornou-se o criador de um dos modelos mais populares entre os games no mundo. Inspirado neste instrumento, ele desenvolveu um instrumento virtual em 2008 para o iPhone, possibilitando a interação física com a ocarina virtual com utilização de captação por microfone, multi-touch e outras ferramentas de manipulação em tempo real, o que também favorece a interação entre diferentes usuários que estejam geograficamente distantes (WANG, 2014).

Conforme Wang (2014), a escolha da ocarina se fundamenta pelas limitações e configurações do dispositivo, assim como a semelhança com o tamanho do instrumento real e seus orifícios (4 furos); foi considerado ainda o contexto adequado para a articulação do microfone ao canal de sopro ("bocal"), além de aspectos expressivos como vibrato e intensidade, de acordo com a imagem abaixo ${ }^{28}$ :

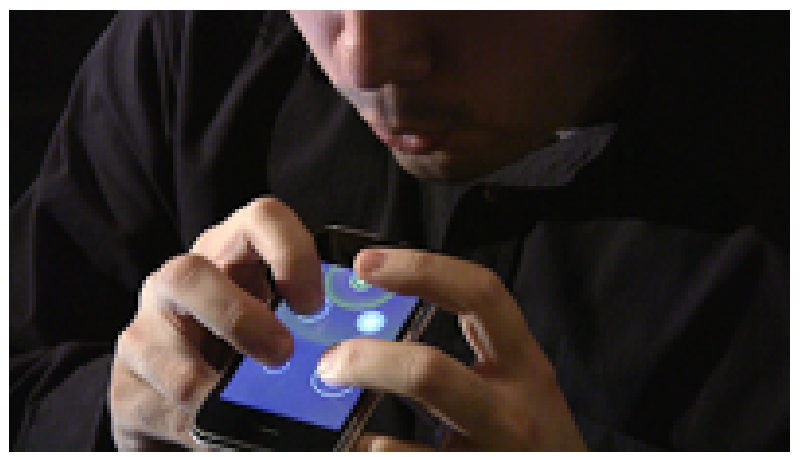

Foto 1: Performance em ocarina virtual, por Ge Wang. Fonte: Página pessoal Ge Wang (2012).

27 Conforme Aliel e Gohn (2012, p.3): "O termo joystick refere-se ao manche ou controle utilizado em videogames que tem como função guiar os personagens nos jogos".

28 Uma performance com o instrumento virtual executada por Ge Wang pode ser conferida em: https://vimeo.com/59391815. Fonte: Página pessoal de Ge Wang. 
É relativamente fácil encontrar ocarinas virtuais compatíveis para diferentes modelos e marcas de dispositivos móveis, com acesso gratuito. Supõe-se que criações como a de Wang tenham subsidiado a adoção da ocarina como ficou conhecida no game The Legend of Zelda: Ocarina of Time ${ }^{29}$ lançado originalmente para Nintendo 64 em 1998, sendo um dos jogos mais vendidos e com maior nota avaliativa de seus consumidores em todos os tempos ${ }^{30}$. Um dos aspectos marcantes desse tipo de recurso é a aproximação de seus usuários do instrumento musical em sua versão virtual, a qual pode também ser uma ponte para o diálogo com o universo de tablaturas e partituras, tópicos em música e até componentes expressivos da performance. Nesse sentido, cabe pensar se essa não pode ser uma forma de cativar novos estudantes de música, numa expansão do ciclo de produção e consumo, de ensino e aprendizagem e grande apelo especialmente entre jovens.

É instigante traçar uma linha do tempo para o instrumento que é considerado o mais antigo da humanidade (LEVITIN, 2010), pensando nas flautas originadas de ossos de animais como fêmur de flamingos e ursos, madeira, cristal, porcelana, barro, metal, plástico e outros materiais, até os instrumentos eletrônicos e virtuais. As flautas vêm sendo um instrumento musical criado e manipulado pela humanidade desde tempos muito remotos, que datam de mais de 40 mil anos atrás (LEVITIN, 2010), e suas variações de formatos e sonoridades estão associadas ao seu contexto sociocultural. Há diferentes tipos de flautas, dos quais inclusive a ocarina perfaz, caracterizando a família de sopros no sistema de bisel ${ }^{31}$.

No que diz respeito à flauta doce, um dos instrumentos mais populares da atualidade e a partir do século 20 utilizado na educação musical, há um vasto repertório da música tradicional de concerto, permeado por obras de renomados compositores, como Johann Sebastian Bach (1685-1750), Antonio Vivaldi (1678-1741), Benjamin Britten (1913-1976) e Luciano Berio (1925-2003). No Brasil, compositores como Osvaldo Lacerda (1927-2011), Bruno Kiefer (1923-1987), Fernando Lewis de Mattos (1963-2018) e Felipe Kirst Adami (1977) compuseram inúmeras obras de caráter artístico ou didático em formações diversas para a flauta doce.

A partir do século 20, o instrumento passa a ser adotado como ferramenta musicalizadora, devido a modelos a preços acessíveis e facilidade técnica na iniciação (CUERVO, 2009). Suas possibilidades de implementação tanto em repertórios e contextos artísticos avançados quanto amplamente utilizados no campo didático, portanto, tornaram a flauta doce um excelente recurso para a prática musical através de recursos disponibilizados na rede e por meio de jogos eletrônicos (CUERVO, 2014). A performance do instrumento se vê favorecida pela enorme gama de recursos na internet, como softwares e aplicativos, videoaulas e materiais didáticos, porém a sua qualidade é tão diversa quanto os seus formatos e conteúdos (CUERVO, 2014).

29 Fonte: Site oficial The Legend of Zelda. Disponivel em: http://www.zelda.com/ocarina3d/.

30 Fonte: Game Rankings. Disponivel em: http://www.gamerankings.com/.

31 O bisel, descrito anteriormente, decorre do tipo de projeção do ar promovido pela embocadura livre, possuindo um ângulo em que ele seja direcionado no canal de ar em forma de aresta ou quina, a ponto de resultar no timbre e intensidade da nota desejada, combinados à articulação e à digitação. Outros tipos de embocadura de instrumentos de sopro diferentes do bisel referem-se às palhetas simples e duplas. 
Em 2010 foi lançado o jogo com versão gratuita JoyTunes Recorder ${ }^{32}$, voltado para o público infantil iniciante até o avançado, com mais de 100 fases desenvolvidas em um repertório de canções facilitadas standard do instrumento. Para a sua implementação, é necessário um microfone simples ligado ao computador.

A análise deste game realizada por Aliel e Gohn (2012) aponta duas diferentes propostas: o Recorder Master para iniciantes, com elementos introdutórios de digitação, percepção e outros aspectos, e o Recorder Express, com aprofundamento de conteúdo e repertório baseado no método de Artie Almeida ${ }^{33}$ (ALIEL; GOHN, 2012). No que se refere à educação musical, o software possibilita mecanismos avaliativos de acompanhamento da progressão do estudante, com riqueza de dados expostos em tabelas e gráficos que refletem a trajetória de desenvolvimento técnico no instrumento, tornando-se acessível ao educador musical após um cadastro simples (ALIEL; GOHN, 2012, p.4).

Esse tipo de game se apresenta como uma alternativa de estudo de um instrumento musical real (não virtual) extremamente cativante, pois agrega aspectos técnicos e exercícios que, em outros contextos, poderiam ser maçantes, mas aqui se tornam uma ferramenta prazerosa de prática deliberada. A ludicidade permeia o layout e as propostas de cada fase do jogo, motivando o estudante a progredir de fases conforme os obstáculos são apresentados. Criado com o objetivo específico de promover a prática instrumental, diferentemente de jogos que promovem a execução instrumental, embora não a tenham como meta e não apresentem uma preocupação didática do progresso do estudante, este jogo propicia a construção de uma performance musical de maneira conectada ao perfil das crianças e jovens de hoje, familiarizados com a gamificação (CUERVO, 2016). Ainda que possua um design voltado para o público infantojuvenil, acredita-se que o apelo de games alcança um amplo escopo de perfis de usuários, expandindo o componente etário, como constatou a autora em sua tese (2016).

Não obstante, não deve ser esquecido o fato de que a prática instrumental informal autônoma, por meio de recursos virtuais ou acessórios de jogos, num longo prazo, pode ocasionar algumas dificuldades técnico-musicais, como nos aspectos da postura e do som. Nesse sentido, o acompanhamento ou orientação de um professor de música é salutar para a condução qualificada da construção da performance do "jogador", pois não há um feedback nessas interfaces do fazer musical durante a interação.

Em sua pesquisa, foi estudada a implementação deste game a um usuário de 9 anos de idade (CUERVO, 2016). O estudante Amadeo possuía 5 anos de educação musical com especialistas na época da coleta, dominando previamente a notação musical convencional e o idioma inglês, cuja adoção é comum em jogos estrangeiros por ele conhecidos. O sujeito demonstrou familiaridade com a interface e solicitou interagir com as fases do game de maneira progressiva desde a inicial, o que depois se mostrou muito fácil para o seu nível técnico-musical. Mesmo achando fácil a execução instrumental correspondente às fases iniciais do jogo, em momento algum mostrou desinteresse, o que talvez possa ressaltar o potencial cativante que a proposta apresenta.

32 Além da flauta doce (recorder, em inglês), o desenvolvedor disponibiliza também o JoyTunes Piano, Piano-Pro. Fonte: https://www. joytunes.com/index.php.

33 Fonte: http://www.artiealmeida.com. 
Amadeo se e deparou com alguns obstáculos na utilização do equipamento demandado pelo jogo, como o ângulo preciso de captação sonora que influenciava na pontuação da performance. Esse aspecto foi notado principalmente no quesito rítmico, pois a velocidade de captação e resposta somados ao volume interferia no resultado. Outro dado que chamou a atenção tanto de Amadeo quanto da pesquisadora foi o fato de que pequenas nuances de sopro que naturalmente afetam a afinação da flauta doce também alteravam a avaliação nas fases do jogo. No que diz respeito ao timbre, foi explorada a possibilidade descoberta pelo sujeito de cantar ao invés de tocar, e, se a afinação fosse precisa, era possível conquistar a pontuação relativa ao contorno melódico. A foto a seguir registra um momento de jogo, no qual AMI visualiza a interface na tela do monitor do computador em seu ambiente doméstico.

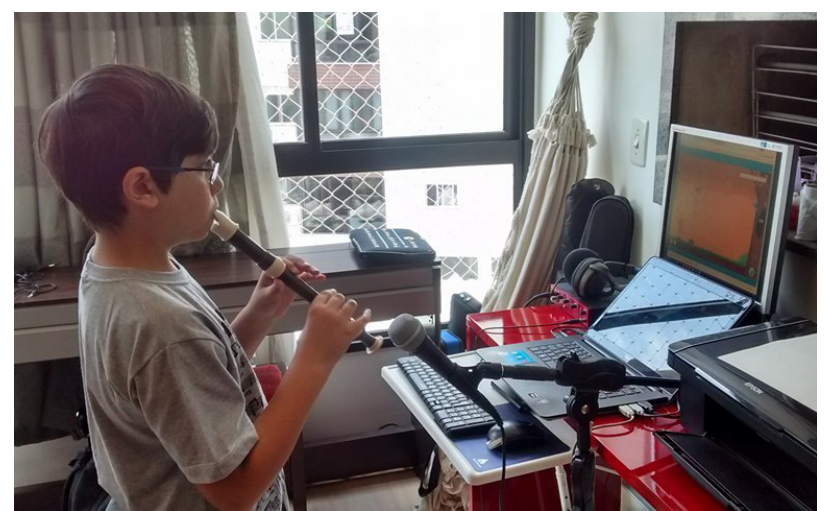

Foto 2: Amadeo jogando JoyTunes com a sua flauta doce (modelo Yamaha 314B).

Fonte: Acervo pessoal da pesquisadora (CUERVO, 2016)

Amadeo apreciou a proposta visual do jogo e achou agradável o acompanhamento instrumental variado em estilos de cada fase, assim como achou empolgante receber o feedback de parabenização do narrador de cada etapa, o que se tornou uma espécie de "troféu" ao final de cada fase. Chegou a permanecer períodos prolongados de até $1 \mathrm{~h}$ praticando o instrumento devido à motivação gerada pela competição lúdica da proposta, o que normalmente não fazia quando se dedicava à execução instrumental das lições semanais de sua aula de música. Outro aspecto positivo do game é a sua variedade de estilos musicais, contemplando música de concerto do repertório standard do instrumento e canções menos convencionais, como de jazz.

Além da execução instrumental de linhas melódicas com e sem acompanhamento, o jogo demanda atividades criativas de improvisação, memória musical, diferenciando-se enormemente de suas experiências práticas na aula de instrumento. Sua fluência e independência ao ligar o equipamento com tranquilidade após a primeira experiência com o game foi semelhante ao console que jogava à época, Wii-u, o qual costuma jogar no mesmo espaço também de forma independente (sem a ajuda de adultos).

Os pontos semelhantes entre jogos eletrônicos de caráter simulatório, como o Guitar Hero, e a execução em instrumentos reais, como o EnjoyRecoder, foram analisados por Aliel e Gohn (2012). Para os autores, esses recursos têm afinidade com os pres- 
supostos defendidos no ensino de música em ambientes de educação a distância, pois atendem a aspectos técnicos, sensoriais e experimentais relativos à prática deliberada com instrumentos. Como explicam os autores:

No JoyTunes, o jogador encontra dados textuais sobre a flauta doce e sua história, propiciando a leitura do conteúdo. Já no nível sensorial, há a necessidade de que elementos sonoros estejam associados aos escritos, para o estabelecimento de conceitos musicais por parte do aluno. No jogo aqui observado, pequenos excertos de peças musicais eruditas e populares são apresentados, em forma de áudio acompanhado de escrita (partitura musical). Finalmente, no nível experimental o autor aponta uma unificação de conteúdos escritos, sonoros e imagéticos para compreensão de processos de ensino e aprendizagem da prática instrumental musical. (ALIEL; GOHN, 2012, p.5-6).

Conforme apontam Aliel e Gohn (2012), o participante é estimulado a tocar com um instrumento real, conduzindo o percurso e as tomadas de decisão da partida. Para os autores, essa ação é um procedimento que desenvolve aspectos técnico-musicais permeados pela ludicidade, com um embasamento didático da proposta. De acordo com a superação de níveis do jogo, novos obstáculos desafiam a concentração e as capacidades de percepção e leitura musical. Dessa forma, são concretizadas tanto possibilidades de aprendizagem autônoma quanto mediadas pelo professor.

Na superação de possibilidades sonoras promovidas pelas NTD com a flauta doce, Villavicencio (2011) analisa a flauta produzida por Barker em 1987, chamada de Electrified recorder, cujo som acústico era mantido como original, contudo com a possibilidade de amplificação. De acordo com a sua visão, após amplificado, o som é "[...] gravado no momento da performance e transformado por meio de uma série de sensores instalados no corpo da flauta. Cria-se assim, usando a eletrônica, uma nova camada sonora, paralela ao som acústico" (VILLAVICENCIO, 2011, p.302). A partir desse estudo, Villavicencio (2011, p.302) desenvolveu a E-Recorder, argumentando que:

A diferença entre os dois instrumentos está somente na geração de sensores que cada um utiliza. Cabe apontar o fato de que o espaço de cinco anos que permeou a idealização de ambos os instrumentos foi suficiente para que toda uma geração de componentes eletrônicos fosse substituída.

A partir do acoplamento desses recursos a uma flauta doce contrabaixo no modelo assinado por Paetzold ${ }^{34}$, o pesquisador conseguiu produzir sons acústicos com possibilidade de controle de materiais previamente gravados por meio de sensores conectados ao instrumento, promovendo um diálogo entre sonoridades acústicas e sintéticas (VILLAVICENCIO, 2014, s/p). Utilizando o sistema MAX/MSP35 programado pelo seu parceiro de pesquisa, Johan van Kreij, e suporte do técnico Lex Van den Broek, foi criado um software chamado de "PIPO", seguido de sua versão mais avançada intitulada

\footnotetext{
34 Fonte: http://www.blockfloetenbau-paetzold.de/.

35 O MAX/MSP é um recurso concebido para a programação visual em MIDI no formato áudio multimídia, bastante utilizado em composição e performance musical. Fonte: http://www.ufrgs.br/mvs/Periodo06-1997-MaxMSP_NEW.html.
} 
de "PIPOTAN", um patch ${ }^{36}$, a qual apresenta uma interface visual que emite dados dos sensores instalados, assim como o gráfico do som registrado no computador. Ao longo de uma década de performance com o instrumento, foi possível aperfeiçoar seus mecanismos, e Villavicencio (2011) destaca o progresso tecnológico que permitiu conectar equipamentos menores, mais potentes e mais leves à E-Recorder, escolhendo uma tela LCD pequena para promover maior autonomia ao intérprete no momento da execução. Com esse recurso, passaram a ser economizadas muitas horas de dedicação à pré-produção envolvendo a flauta, e o instrumentista consegue dedicar-se com mais fluência às suas improvisações livres solistas (VILLAVICENCIO, 2014).

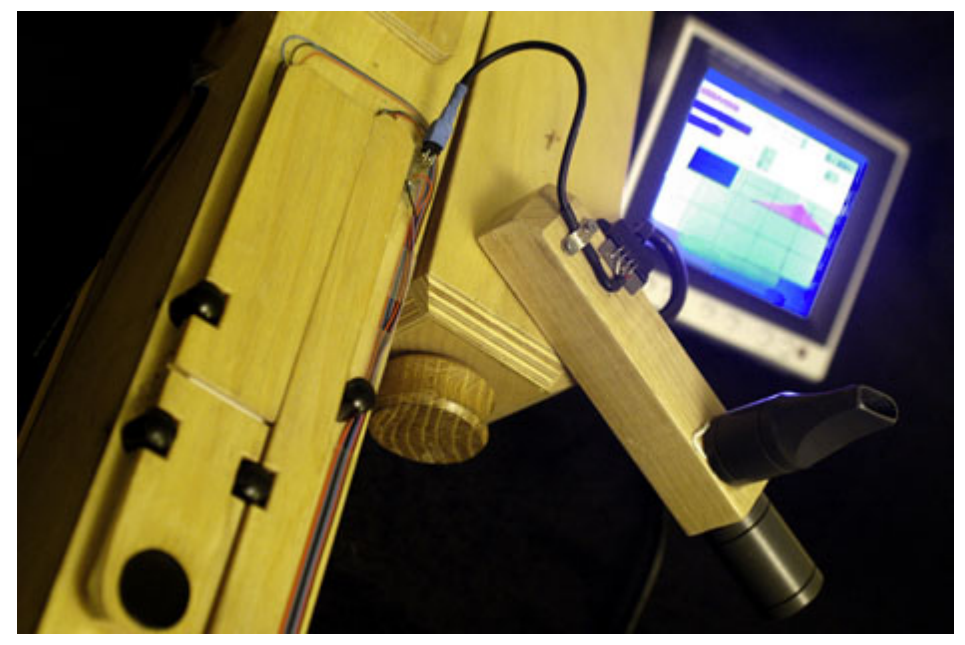

Foto 3: E-Recorder de Cesar Villavicencio. Fonte: Acervo pessoal do músico.

Villavicencio (2011) resgata a história do instrumento ao mencionar a inserção de recursos tecnológicos avançados para sua época, como no caso da flauta doce barroca, com a duplicação dos orifícios inferiores e conquista de cromatismo mais preciso, os diferentes tipos de diâmetros e formatos do tubo de ar, o acoplamento de chaves etc. Para ele, a interpretação historicamente orientada também envolve a música do século 20, considerando que as intenções originais do compositor nem sempre ficam acessíveis em registros ou são possíveis de serem elucidadas pelo próprio. Além disso, conforme argumenta, as condições acústicas e o contexto sociocultural do evento são também fatores que interferem na performance musical (VILLAVICENCIO, 2011).

Contudo, cabe dizer que a E-Recorder não é um instrumento acessível, ainda que seja fruto de uma iniciativa inovadora, criativa e contributiva para o aumento do repertório idiomático da flauta doce. A sua tecnologia é especializada e possui um custo alto tanto do instrumento quanto dos equipamentos de suporte. Como uma alternativa a esse contexto, Barcellos et al. (2012) desenvolveram uma flauta doce eletroacústica de baixo custo, visando difundir a sua implementação em conjunturas socioeconômicas limitadas ou diversas. O grupo de pesquisadores desenvolveu um software livre e um dis- 
positivo anexado a uma flauta doce convencional. Houve criação de repertório musical específico para o protótipo ao longo do projeto-piloto, cujos resultados demonstraram que a interface interativa entre a flauta doce e os recursos de música eletroacústica não somente era viável como artística e didaticamente satisfatória.

Essas contribuições, mesmo que em suas fases exploratórias e prototípicas, podem enriquecer enormemente as estratégias pedagógicas envolvendo o ensino do instrumento. Ao considerar a adoção ampla da flauta doce em projetos sociais e currículo escolar, recursos como este de Barcellos e seus colaboradores (2012) podem ser cruciais na promoção da música contemporânea eletroacústica, eletrônica e de manipulação e improvisação ao vivo. São possibilidades atraentes na modernização do ensino do instrumento, a qual apresenta carências acentuadas ao insistir em perpetuar, no Brasil, um ensino tradicional fundamentado em métodos impressos criados em meados do século 20, cujo estudante é mero executor de repertórios e exercícios técnicos prévia e detalhadamente indicados para um desenvolvimento sistemático.

Pelo menos dois apps gratuitos de aprendizagem da flauta doce vêm sendo largamente utilizados no Brasil, promovendo, a partir da portabilidade, o estudo do instrumento ao alcance do celular. O app gratuito Flauta doce: Digitação, do desenvolvedor MusicaTi ${ }^{37}$, focando nas lições de nível iniciante, apresenta aspectos introdutórios da teoria musical, com destaque para a digitação da flauta. Com uma interface amigável e linguagem acessível, o MusicaTi vem sendo empregado pela autora em algumas experiências, como forma de complementar e enriquecer as orientações discutidas em aulas presenciais, além de processos de aprendizagem autônoma. Seu áudio possui um timbre pobre que não condiz com o som da flauta doce. Outro recurso estudado é o app Aprender Flauta Doce ${ }^{38}$, que tem como pontos fortes a possibilidade de escolha de diferentes tipos de flauta doce (em fá ou dó, germânica ou barroca etc.), a riqueza de referências que somam a posição por meio de fotos, desenhos e notação musical, e uma interface visualmente fácil de entender. Um aspecto interessante a respeito da acessibilidade é a possibilidade de apreciar vídeos instrucionais no YouTube a partir do ícone interno do app, nos quais poderão ser conhecidas músicas de diferentes níveis técnicos.

Um dos pontos negativos desabonadores é que o áudio do app é da flauta transversa, gerando um timbre modelo diferente da flauta doce. Os apps também prejudicam uma formação integral, pois não abordam aspectos basilares, como respiração e articulação, dois dos três pilares da execução do instrumento que se somam à digitação. Desse modo, cabe mencionar a importância do professor, mais uma vez, cujo papel crucial em orientar de maneira qualificada os procedimentos técnicos de digitação e articulação, a expressividade, o processo respiratório e a adequada às necessárias adaptações anatômicas e ergonômicas da execução instrumental faz toda a diferença no desenvolvimento do estudante.

37 Fonte: https://play.google.com/store/apps/details?id=air.DigitacaoFlautaDoce.

38 Fonte: https://play.google.com/store/apps/details?id=urokimusic.com.HowToPlayRecorder\&hl=pt_BR\&rdid=urokimusic.com.HowToPlayRecorder\&pli=1. 


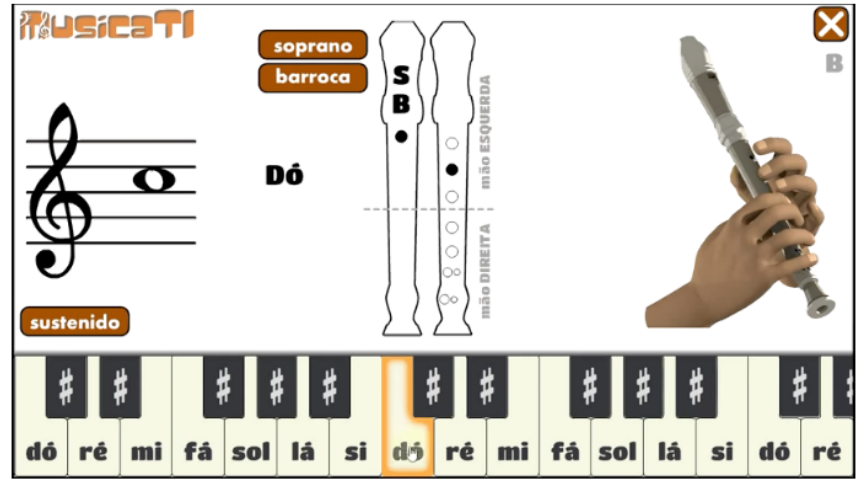

Fig. 4: Interface do app Musicati, nota dó.

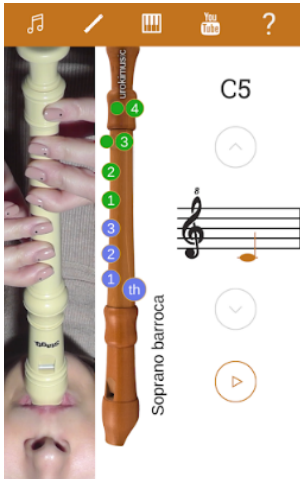

Fig. 5: Interface do app

Aprender Flauta Doce, nota dó.

Na prática pedagógica de Cuervo e Maffioletti $(2012 ; 2016)$ da disciplina Práticas Musicais do curso de Pedagogia da UFRGS do curso de Pedagogia da UFRGS, passou a ser adotada a indicação de apps com fins didáticos, buscando ampliar as práticas realizadas em sala de aula ao proporcionar o estudo orientado e autônomo em casa, especialmente no âmbito dos fundamentos da teoria musical, da prática vocal e da instrumental, esta centrada na flauta doce. Dessa maneira, a prática musical é incentivada de modo a aperfeiçoar questões técnicas que demandam dedicação regular e que não apresentam progresso expressivo quando são exercitadas somente em aula. A análise comparativa do desempenho dos estudantes em relação às turmas anteriores à adoção dessa estratégia torna possível afirmar que a proposta é eficaz. Na turma observada, obteve-se ótima receptividade junto, sendo constatado que 12 dos 16 estudantes baixaram o app (livre e gratuito) indicado num prazo de até duas semanas posteriores. Constatou-se, também, que a estratégia originou motivação adicional no desempenho individual de estudo de música, e que os jovens estudantes demonstraram familiaridade com os procedimentos tecnológicos e possuíam dispositivos móveis adequados para tal empreitada.

\section{Considerações finais}

A união das NTD à prática musical, especialmente por instrumentos musicais extremamente populares, como o canto e a flauta doce e seu estudo permitido por um dispositivo móvel, democratiza o acesso desses saberes e práticas. Se antes desse fenômeno as aulas eram limitadas a espaços e tempos específicos, retendo o conhecimento a partir de instruções específicas do ensino e de materiais tradicionais, agora há uma abertura de possibilidades imensuráveis. Recursos que promovem o estudo autônomo, que desdobram e qualificam o momento presente da aula em situações remotas, e permitem inclusive a autoaprendizagem, são comuns na cultura digital. 
É possível afirmar, portanto, que modalidades novas envolvidas no fazer musical e manifestações de musicalidade são suscitadas a partir do emprego das NTD, assim como atividades convencionais também são impactadas pelas transformações tecnológicas promovidas em tempos e lugares diversos. Essas possibilidades transcendem a concepção tradicional de execução instrumental e manipulação da partitura e ampliam o escopo de capacidades técnicas e expressivas comumente atribuídas à execução musical.

Sob essa ótica, é coerente afirmar que a educação musical pode se beneficiar pela implementação de softwares e aplicativos, principalmente se forem pensados como modos de promover maior interação e criatividade no estudo de um instrumento musical. Essa performance musical deve então ser pensada devidamente contextualizada ao tempo e à vivência sociocultural de seus sujeitos. Estéticas, estratégias e abordagens influenciadas vêm transformando as relações entre os compositores, os intérpretes e o público apreciador, e também se manifestam nos processos de concepção, produção, performance e consumo de música, conforme discutiu CUERVO (2016) em sua pesquisa.

Essas experiências, enfim, também vêm ao encontro de uma expansão das concepções e práticas de musicalidade, promovendo o enriquecimento de recursos interpretativos que terão reflexo direto na performance ao vivo.

\section{Referências}

ANDES. Programa Future-se representa a extinção da Educação Federal Pública. Brasília: Sindicato Nacional dos Docentes do Ensino Superior, 2019. Disponível em: https://www.andes.org.br/conteudos/noticia/entidades-do-setor-da-educacaoprograma-future-se-representa-a-extincao-da-educacao-federal-publica1. Acesso em: 20 jul. 2019.

ALIEL, Luzilei; GOHN, Daniel Marcondes. Jogos Eletrônicos Musicais e EAD: Contingência de Ferramentas para aprendizagem instrumental. In: SIED SIMPÓSIO INTERNACIONAL DE EDUCAÇÃO À DISTÂNCIA; ENPED - ENCONTRO DE PESQUISADORES DE EDUCAÇÃO À DISTÂNCIA, 2012, São Carlos. Anais [...]. São Carlos: USFCAR, 2012.

BARCELLOS, Marco Antônio; SANTOS, Raphael Souza; OLIVEIRA, Liduino José Pitombeira; PASSOS, Paulo Márcio Coutinho. Flauta Doce Eletroacústica de Baixo Custo. In: XXII CONGRESSO DA ASSOCIAÇÃO NACIONAL DE PESQUISA E PÓSGRADUAÇÃO EM MÚSICA. Anais... João Pessoa, UFPR, 2012.

BAUER, Willian. Music learning and technology. New Directions: A Journal of Scholarship, Creativity and Leadership in Music Education, n. 1, 2014. Disponível em: http://nd.music.msu.edu/music-learning-technology-william-bauer/. Acesso em: 12 mar. 2019. 
CALLAGHAN, J.; THORPE, W.; DOORN, J. The science of singing and seeing. In: PARNCUTT, R.; KESSLER, A.; ZIMMER, F. (Eds.). Proceedings of the Conference on Interdisciplinary Musicology (CIM04). 2014, p. 15-18. Graz, Austria. Disponível em: http://gewi.uni-graz.at/ cim04/. Acesso em: 3 mar. 2019.

CUERVO, Luciane. Musicalidade na performance com a flauta doce. Dissertação (Mestrado em Educação). Universidade Federal do Rio Grande do Sul, Porto Alegre, 2009.

Educação musical e a ideia de arquiteturas pedagógicas: práticas na formação de professores da geração "nativos digitais". Revista da ABEM, Associação Brasileira de Educação Musical, v. 20, n. 29, p. 62-77, jul./dez. 2012.

Musicalidade da performance na cultura digital: estudo exploratóriodescritivo sob uma perspectiva interdisciplinar. Tese (Doutorado Informática na Educação). Universidade Federal do Rio Grande do Sul, Porto Alegre, 2016.

CUERVO, Luciane; DIAS, Marcelo. Práticas Vocais no contexto da Cultura Digital: um estudo sobre as tecnologias de feedback visual. In: XXI CONFERENCIAL REGIONAL LATINOAMERICANA DE EDUCACIÓN MUSICAL E IV CONFERECIA REGIONAL PANAMERICANA DE EDUCACIÓN MUSICAL, 2019, Resistencia - Argentina. Anais... (no prelo). Argentina, Internacional Society for Music Education (ISME). Resistencia, Argentina, jul.2019.

CUERVO, Luciane; WELCH, Graham, MAFFIOLETTI, Leda de Albuquerque; REATEGUI, Eliseo. Musicalidade humana sob o prisma cognitivoevolucionista: do Homo sapiens ao Homo digitalis. Revista OPUS, 23(2), 2019, p. 216-242. Doi:10.20504/ opus2017b2310

Cultura digital e docência: possibilidades para a educação Musical. Revista Acta Scientiarum Educação - formação de professores. Disponível em: http:// periodicos.uem.br/ojs/actalSSN on-line: 2178-5201 Doi: 10.4025/actascieduc. v40i1.34442Acta Sci. Educ., v. 41(1), e34442, 2019

DINIZ, Mariana. Entidades científicas são contra o fim do Ministério da Ciência e Tecnologia - Seção Notas e Manifestos. Plataforma Política Social, 2018. Disponível em: https://plataformapoliticasocial.com.br/entidades-cientificas-sao-contra-o-fimdo-ministerio-da-ciencia-e-tecnologia/. Acesso em: 10 abr. 2019.

GABRIELSSON, Alf. Music Performance Research at the Millennium. Psychology of Music, Society for Education, Music and Psychology Research (SEMPRE), London, v. 31, n. 3, p. 221- 272, 2003. 
GOHN, Daniel Marcondes. Educação musical à distância: abordagens e experiências. E-book. São Paulo: Cortez, 2013.

Educação Musical com as Tecnologias da EAD. In: SILVA, H. L.; ZILLE, J. A. B. Música e Educação. Série Diálogos com o Som. E-book. 2015. Disponível em: https:// dl.dropboxusercontent.com/u/30521112/Di\%C3\%A1logos-com-o-Som-Vol2-Ebook. pdf.pdf. Acesso em: 20 mar. 2019.

FLORES, Luciano Vargas. Uma Infraestrutura para Design da Interação Musical com Dispositivos Móveis Cotidianos. 2014. 142 f. Tese (Doutorado) - Programa de PósGraduação em Computação, Universidade Federal do Rio Grande do Sul, Porto Alegre, 2014.

HARGREAVES, David. Within You Without You: Music, Learning and Identity. Electronic Musicological Review, Curitiba, v. 9, oct. 2005. Disponível em: http://www.rem.ufpr. br/_REM/REMv9-1/hargreaves-engl.pdf. Acesso em: 12 mar. 2019.

IBGE - INSTITUTO BRASILEIRO DE GEOGRAFIA E ESTATÍSTICA. Síntese de Indicadores Sociais: uma análise das condições de vida da população brasileira. Rio de Janeiro: IBGE, 2018. Disponível em: https://biblioteca.ibge.gov.br/visualizacao/livros/liv101629. pdf. Acesso em: 2 mar. 2019.

KRAMER, Jonathan. The Impact of Technology on the Musical Experience. 1997. Disponível em: http://symposium.music.org/index.php?option=com_ k2\&view=item\&id=9390:the-impact-of-technology-on-the-musicalexperiencefltemid=128. Acesso em: 12 set. 2016.

LEVITIN, Daniel. A música em seu cérebro: a história de uma obsessão humana. São Paulo: Civilização Brasileira, 2010.

MULDER, Axel G. E. Virtual musical instruments: accessing the sound synthesis universe as a performer. In: ANNUAL CONGRESS OF THE BRAZILIAN COMPUTING SOCIETY (SBC), 14., 1994, Proceedings of the first Brazilian Symposium on Computer Music, Caxambu. Anais [...]. UFMG: SBC, 1994. p. 243-250.

$\mathrm{OH}$, Changhoon; LEE, Taeyoung; KIM, Yoojung; PARK, SoHyun; KWON, Saebom; SUH, Bongwon. Us vs. Them: Understanding Artificial Intelligence Technophobia over the Google DeepMind Challenge Match. Human Computer Integration, Denver, CHI 2017, may 6-11, 2017. 
ONU - Organizações das Nações Unidas. The State of Broadband 2015:

Broadband as a Foundation for Sustainable Development. A report The Broadband Commission for Digital Development. ONU, sept. 2015. Disponivel em: http://www. broadbandcommission.org/Documents/reports/bb-annualreport2015.pdf. Acesso em: 12 jul. 2019.

PADILHA, Valquíria; BONIFÁCIO, Renata, Obsolescência planejada: armadilha silenciosa na sociedade de consumo. Le Monde Diplomatique Brasil, ano 7, n. 74, set. 2013.

SCHLOSS, Andrew. Using contemporary technology in live performance: the dilemma of the performer. Journal of New Music Research, v. 31, n. 1, 2002. Disponível em: https://people.finearts.uvic.ca/ aschloss/publications/JNMR02_Dilemma_of_the_ Performer.pdf. Acesso em: 14 abr. 2019.

SILVA, Marco. Internet na escola e inclusão. In: BRASIL. Tecnologias na escola. Brasília, DF: Portal MEC-SEED, [s.d.]. p. 75-79. Disponível em: http://portal.mec.gov.br/seed/ arquivos/pdf/2sf.pdf. Acesso em: 12 jun. 2019.

THE MUSIC COMMISSION. Retuning our ambition for music learning: every chuld taking music futher. 2019. Disponível em: http://www.musiccommission.org.uk/. Acesso em: 2 jul. 2019.

TEIXEIRA, Adriano Canabarro. Inclusão digital: novas perspectivas para a informática educativa. ljuí: Editora Unijuí, 2010.

VILLAVICENCIO, Cesar. A flauta doce historicamente informada. Ouvirouver, Uberlândia, v. 7 n. 2, p. 308-324, jul./dez. 2011.

E-recorder. Página pessoal, 2014. Disponível em: http://www.cevill.com/pt/erecorder/. Acesso em: 12 mar. 2019.

XYDAS, Spiros Daniel. Transforming Music Classes and Rehearsals with Compositions and Ipads: Reflections from a Mid-Carrer Music Educator. Tempo - The Official Magazine of the New Jersey Music Educators Association, Troy/Michigan, Baker Middle School, p. 52-53, mar. 2014.

WANG, Ge. Ocarina: Designing the iPhone's Magic Flute. Center for Computer Research in Music and Acoustics (CCRMA) Department of Music Stanford University. Computer Music Journal, Massachusetts Institute of Technology, v. 38, n. 2, p. 8-21, 2014. 
Ocarina 2 Medley. Página pessoal de Ge Wang. Disponível em: http://www. gewang.com/ocarina/. Acesso em: 12 mar. 2016.

WEBSTER, Peter Richard. Computer-Based Technology and Music Teaching and Learning. In: COLWELL, R.; RICHARDSON, C. (Eds.). The New Handbook of Research on Music teaching and Learning. New York: Oxford University Press, 2002a. p. 416-435.

WELCH, Frederick Graham. Investigar o desenvolvimento da voz e do canto ao longo da vida. Revista Música, Psicologia e Educação, n. 5, p. 5-20. 2003.

Singing as communication. In: MIELL, D.; MACDONALD, R.; HARGREAVES, D. (Eds.). Musical Communication. New York: Oxford University Press, 2005b. p. 239-259. Disponível em: https://www.researchgate.net/publication/265579139_Singing_as_ communication. Acesso em: 12 abr. 2019.

Os maiores benefícios da música. In: SIMPÓSIO DE COGNIÇÃO E ARTES MUSICAIS, 8., 2012, Florianópolis. Anais [...]. Florianópolis: UDESC/Departamento de Música, 2012. p. xiii-xvii.

WHITACRE, Eric. A virtual choir 2.000 voices strong. Conferência TED, abr. 2011. Disponível em: https://www.ted.com/talks/eric_whitacre_a_virtual_choir_2_000_ voices_strong/transcript. Acesso em: 2 mar. 2019.

WILLIAMS, David Brian; WEBSTER, Peter Richard. Experiencing Music Technology. 3. ed. USA: Schirmer Reference, 2006.

WILSON, Pat H.; THORPE, William C; CALLAGHAN, Jean. Looking at singing: does real-time visual feedback improve the way we learn to sing? Sydney, Australia: School of Communication Sciences and Disorders, University of Sydney, 2015. Disponível em: https://www.afpc-evta-france.com/wp-content/uploads/sites/10/2015/02/72feeback-visuel-et-apprentissage-chant.pdf. Acesso em: 1 mar. 2019.

WOLFFENBÜTTEL, Cristina Rolim. Música nas escolas públicas municipais do Rio Grande do Sul. Revista Brasileira de Educação, v. 22 n. 71. Disponível em: http://www. scielo.br/pdf/rbedu/v22n71/1809-449X-rbedu-22-71-e227181.pdf. Acesso em: 2 mar. 2019. 